\title{
Topical pimecrolimus inhibits high-dose UVB irradiation-induced epidermal Langerhans cell migration, via regulation of TNF- $\alpha$ and E-cadherin
}

This article was published in the following Dove Press journal:

Drug Design, Development and Therapy

10 October 2014

Number of times this article has been viewed

\author{
ZhiQiang Yin ${ }^{1, *}$ \\ JiaLi $X u^{2, *}$ \\ BingRong Zhou' \\ Di Wu' \\ Yang $\mathrm{Xu}$ \\ JiaAn Zhang' \\ Dan Luo'
}

'Department of Dermatology, ${ }^{2}$ Department of Oncology, First Affiliated Hospital of Nanjing Medical University, Guangzhou Road, Nanjing, Jiangsu, People's Republic of China

*These authors contributed equally to this work
Correspondence: Dan Luo Department of Dermatology, the First Affiliated Hospital of Nanjing Medical University, Guangzhou Road, Nanjing, Jiangsu, 210029, People's Republic of China

Tel +86013655187928

Fax +8625837I 6602

Email daniluo2005@sina.com
Background: Topical pimecrolimus has been shown to reverse epidermal CD1 $\mathrm{a}^{+}$Langerhans cell reduction induced by high-dose ultraviolet (UV)B irradiation, but the mechanism is still unclear. This study aimed to investigate the possible mechanism of the effect of pimecrolimus on high-dose UVB-irradiated epidermal Langerhans cells.

Methods: Forty human foreskin tissues were divided into four groups: control; pimecrolimusonly; UVB-only; and UVB + pimecrolimus. All tissues were cultured, and each tissue was cut into four pieces, corresponding to four time points ( 0 hours, 18 hours, 24 hours, and 48 hours). We collected the tissues and culture medium at each time point. The percentage of CD1 a cells in medium was detected by flow cytometry. The tissues were detected for messenger $(\mathrm{m}) \mathrm{RNA}$ and protein expression of tumor necrosis factor (TNF)- $\alpha$, interleukin (IL)-1 $\beta$, and E-cadherin, by reverse-transcription polymerase chain reaction (PCR) and Western blot.

Results: At 18 hours, 24 hours, and 48 hours, the $\mathrm{CD}^{2} \mathrm{a}^{+}$cells in the culture medium of the UVB-only group and the UVB + pimecrolimus group were significantly more than in the control group, while the CD1 ${ }^{+}$cells of the UVB + pimecrolimus group was less than of the UVB-only group. For both the UVB-only group and UVB + pimecrolimus group, TNF- $\alpha$ expression (by both reverse-transcription PCR and Western blot) of the tissues was clearly higher and E-cadherin expression was significantly lower compared with the control group, at 18 hours, 24 hours, and 48 hours. For the UVB + pimecrolimus group, TNF- $\alpha$ was clearly lower and E-cadherin was significantly higher compared with the UVB-only group.

Conclusion: Topical pimecrolimus inhibited epidermal Langerhans cell migration induced by high-dose UVB irradiation, via regulation of TNF- $\alpha$ and E-cadherin.

Keywords: pimecrolimus, UVB, Langerhans cell, TNF- $\alpha$, E-cadherin

\section{Introduction}

Topical calcineurin inhibitors, including pimecrolimus cream and tacrolimus ointment, have good therapeutic effect on atopic dermatitis and other inflammatory skin diseases, where the therapeutic mechanism is to block T-cell proliferation. ${ }^{1}$ Martires et $\mathrm{al}^{2}$ showed that low-dose, short-term ultraviolet (UV) irradiation-induced changes were minimally affected by pimecrolimus, which showed there were more epidermal human leukocyte antigen (HLA)-DR + Langerhans cells (LCs) and CD83 ${ }^{+} \mathrm{LC}$ in a pimecrolimus + UV group compared with a UV-only group. Our previous study found a single $180 \mathrm{~mJ} / \mathrm{cm}^{2}$ UVB irradiation obviously decreased the numbers of epidermal $\mathrm{CD}^{+} \mathrm{a}^{+}$(and langerin +) LCs at 18 hours, 24 hours, and 48 hours; however, pimecrolimus cream could reverse these changes, and UVB combined with pimecrolimus treatment had no effect on human LC maturation. ${ }^{3}$ Kölgen et $\mathrm{al}^{4}$ reported that apoptosis 
and migration might be the possible mechanisms for single high-dose UVB irradiation-induced significant epidermal LC depletion in human skin, and especially, the increased migration of LCs. Many cytokines, adhesion molecules, and chemokines play roles in the process of epidermal LC migration. The increase of tumor necrosis factor (TNF)- $\alpha$ and interleukin (IL)-1 $\beta$ expression, and the decrease of E-cadherin expression all promote LC migration from epidermis to dermis. ${ }^{5,6}$

This study aimed to investigate the effects of pimecrolimus $1 \%$ cream combined with high-dose UVB irradiation on epidermal LC migration, and the effects of pimecrolimus on TNF- $\alpha$, IL-1 $\beta$, and E-cadherin expression that related to LC migration after UVB irradiation.

\section{Materials and methods}

\section{Ethics statement}

This study was approved by the institutional review board of Nanjing Medical University, Nanjing, People's Republic of China (approval number 2011-SRFA-023). Written, informed consent was obtained from all participants before taking part in this research.

\section{Study design}

We obtained 40 fresh human foreskin tissues from Department of Urology by circumcision. The patients were 18-30 years old and randomly divided into four groups, with each group having ten tissues, as follows: control group; pimecrolimus-only group (tissues were applied once with topical pimecrolimus, on the epidermis); UVB-only group (tissues irradiated once with $180 \mathrm{~mJ} / \mathrm{cm}^{2} \mathrm{UVB}$, on the epidermis); and UVB + pimecrolimus group (tissues were applied on the epidermis with topical pimecrolimus after UVB irradiation). The subdermal tissue was removed by scraping with forceps, and each tissue cut into four pieces of $0.5-1.0 \mathrm{~cm}$. This was followed by three washings with $0.9 \% \mathrm{NaCl}$ for 5 minutes, and then tissues were cultured dermal side down in $1 \mathrm{~mL}$ media (Roswell Park Memorial Institute [RPMI] with 10\% fetal bovine serum [FBS], $55 \mathrm{mM} \beta$-mercaptoethanol, $2 \mathrm{mM}$ glutamine, 100 $\mu \mathrm{g} / \mathrm{mL}$ streptomycin, and $100 \mathrm{U} / \mathrm{mL}$ penicillin) per well of 24-well tissue culture plates. ${ }^{7}$

The source of UVB was a BLE-1T158 UV lamp (Spectronics Corp., Westbury, NY, USA). The UVB dosage was quantified using a Waldmann UV meter (model number 585,100; Herbert Waldmann GmbH \& Co., KG, VillingenSchwenningen, Germany), and $180 \mathrm{~mJ} / \mathrm{cm}^{2}$ UVB was delivered once to the epidermal side of the tissues. After
UVB irradiation (or without UVB irradiation), pimecrolimus $1 \%$ cream (Elidel ${ }^{\circledR}$; Novartis Pharmaceuticals Corp., Basel, Switzerland) was applied on the epidermis of the tissues. By using sterile cotton swab, a thin layer of pimecrolimus was delivered to the epidermis, and then we kept dabbing, with pressure, for 30 seconds. Ten minutes after application or irradiation, to each well was added $1 \mathrm{~mL}$ culture medium, to immerse the whole tissue. All tissues were cultured at $37^{\circ} \mathrm{C}$. We set four time points, as follows: 0 hours, 18 hours, 24 hours, and 48 hours. For each group, each tissue was cut into four pieces, corresponding to the four time points. The detailed information of preparation of the skin tissues, UVB irradiation, and topical treatment was described in our previous study. $^{3}$

After treatment, we collected the culture medium and respective tissues at each time point. The percentage of $\mathrm{CD} \mathrm{a}^{+}$cells in the medium was detected by means of flow cytometry. Part of each collected tissue was frozen and prepared for detecting the messenger (m)RNA expression of cytokines and molecules (TNF- $\alpha$, IL- $1 \beta$, and E-cadherin) related to LC migration, by means of reverse-transcription polymerase chain reaction (RT-PCR). Cytokines and molecules showing significant change would be further detected at the protein level by using Western blot.

\section{Flow cytometry}

The cells in the culture medium were collected by centrifugation and then washed two times with phosphate-buffered saline (PBS). After centrifugation (2,000 rpm, 5 minutes), the cells were recollected. Then, $100 \mu \mathrm{L}$ serum-free medium was added, and then $20 \mu \mathrm{L}$ FITC anti-human CD1a Antibody (BioLegend, Inc., San Diego, USA) was added with mixing, and the samples were incubated at room temperature for 15 minutes. After incubation, cells were washed in PBS to remove excess antibodies and then were collected by centrifugation (2,000 rpm, 5 minutes). Finally, $500 \mu \mathrm{L}$ serum-free medium was added to resuspend the cells, and cells were analyzed on a FACSCalibur ${ }^{\mathrm{TM}}$ flow cytometer (BD Biosciences, Franklin Lakes, NJ, USA), with excitation wavelength at $488 \mathrm{~nm}$ and emission wavelength at $530 \mathrm{~nm}$.

\section{RT-PCR}

Total mRNA was extracted from part $(50 \mathrm{mg})$ of the aforementioned collected tissue, using TRIzol ${ }^{\circledR}$ reagent (Invitrogen; Life Technologies Corp., Carlsbad, CA, USA). First-strand complementary (c)DNA was synthesized from 2 $\mu \mathrm{g}$ of total RNA: RNA was incubated at $42^{\circ} \mathrm{C}$ for 1 hour with M-MuLV Reverse Transcriptase (Thermo Fisher Scientific 
Inc., Waltham, MA, USA) following oligo(dT) priming, and then the enzyme was denatured at $70^{\circ} \mathrm{C}$ for 10 minutes. PCR amplification was performed in a total volume of $50 \mu \mathrm{L}$ containing $1 \mu \mathrm{L}$ template cDNA. Primer sequences are shown in (Table 1). PCR products were analyzed by gel electrophoresis ( $2 \%$ agarose gel). Analysis of the data was performed using BandScan 4.3 software. The gene expression was semiquantitated after normalizing with glyceraldehyde-3phosphate dehydrogenase (GAPDH) gene.

\section{Western blot}

Part (100 mg) of the collected tissues was cut into pieces and homogenized in cold lysis buffer containing protease inhibitor. Centrifugal separation was conducted, at $4^{\circ} \mathrm{C}$, at 10,000 rpm for 5 minutes. The upper layer of the solution was tested for protein using the Bradford method. ${ }^{8}$ Sodium dodecyl sulfate polyacrylamide gel electrophoresis (SDS-PAGE) was performed. The primary antibody was added (rabbit antibody TNF- $\alpha$ [diluted 1:500]; rabbit antibody E-cadherin [diluted 1:500]; and $\beta$-actin antibody [diluted 1:1,000] [Beijing Biosynthesis Biotechnology Co., Ltd, Beijing, People's Republic of China]), and the nitrocellulose filter membrane was incubated at $4^{\circ} \mathrm{C}$ throughout the night, then was washed prior to incubation with the secondary antibody (diluted at $1: 1,000)$, and finally, marked by horseradish peroxidase at $37^{\circ} \mathrm{C}$ for 1 hour. Quantification was performed with Gel-Pro Analyzer software version 4 (Media Cybernetics, Rockville, MD, USA).

\section{Statistical analysis}

PASW Statistics for Windows, Version 18 software was used for data analysis, and the format mean \pm standard deviation (SD) was used to indicate measurement data. All tests were two-sided, using paired $t$-test for two samples at different time points in the same group, and the comparison between groups at the same time point was done with independent samples $t$-test. $P<0.05$ was considered statistically significant.

\section{Results \\ Flow cytometry detection of the percentage of $\mathrm{CDIa}^{+}$cells in the culture medium}

The percentage of $\mathrm{CD} 1 \mathrm{a}^{+}$cells showed a negative result at 0 hours for each group. At 18 hours, all four groups detected the $\mathrm{CD}_{1 \mathrm{a}}{ }^{+}$cells. Figure 1 shows that for each group, from 18 hours to 24 hours and 24 hours to 48 hours, the percentages of $\mathrm{CD} 1 \mathrm{a}^{+}$cells showed a significant increase $(P<0.01)$. For the pimecrolimus-only group, the percentage of $\mathrm{CD} 1 \mathrm{a}^{+}$ cells had no significant difference compared with the control group at 18 hours $(P=0.88), 24$ hours $(P=0.65)$, and 48 hours ( $P=0.35$ ). At 18 hours, 24 hours, and 48 hours, the percentage of $\mathrm{CD}_{1} \mathrm{a}^{+}$cells of the control group was significantly less than that of the UVB + pimecrolimus group and UVB-only group $(P<0.01)$, while the percentage of $\mathrm{CD}^{2} \mathrm{a}^{+}$cells of the UVB-only group was significantly more than that of the $\mathrm{UVB}+$ pimecrolimus group $(P<0.01)$.

\section{RT-PCR detection of the mRNA expression of TNF- $\alpha$, IL-I $\beta$, and $\mathrm{E}$-cadherin in the tissues}

Figure $2 \mathrm{~A}, \mathrm{~B}$, and $\mathrm{E}$ shows that at each time point, the mRNA level of TNF- $\alpha$ of the pimecrolimus-only group had no significant difference compared with the control group $(P>0.05)$. The TNF- $\alpha$ mRNA level had a significant increase from 0 hours to 18 hours, 18 hours to 24 hours, and 24 hours to 48 hours $(P<0.01)$, for both the UVB-only group and UVB + pimecrolimus group. At 18 hours, 24 hours, and 48 hours, the TNF- $\alpha$ mRNA level of the UVB-only group was clearly higher than that of the control group $(P<0.01)$. For the UVB + pimecrolimus group, the TNF- $\alpha$ mRNA level was also significantly higher than both the pimecrolimus-only group and control group at the same time points $(P<0.01)$ but was clearly lower in comparison with the UVB-only group $(P<0.01)$.

Table I Primers for the target genes

\begin{tabular}{lll}
\hline Target genes & Primers & Product size (bp) \\
\hline GAPDH & Sense: 5-AAGGTCGGAGTCAACGGATTT-3 & 352 \\
& Antisense: 5-AGATGATGACCCTTTTGGCTC-3 & \\
TNF- $\alpha$ & Sense: 5-CGCCACCACGCTCTTCTGC-3 & 354 \\
& Antisense: 5-ACGGCGATGCGGCTGATG-3 & \\
IL-I $\beta$ & Sense: 5-CAGGCCGCGTCAGTTGTTGT-3 & 195 \\
& Antisense: 5-CCGGAGCGTGCAGTTCAGTG-3 & \\
& Sense: 5-CCAAAGCCTCAGGTCATAAACA-3 & 126 \\
& Antisense: 5-TTCTTGGGTTGGGTCGTTGTAC-3
\end{tabular}

Abbreviations: GADPH, glyceraldehyde-3-phosphate dehydrogenase; TNF, tumor necrosis factor; IL, interleukin. 

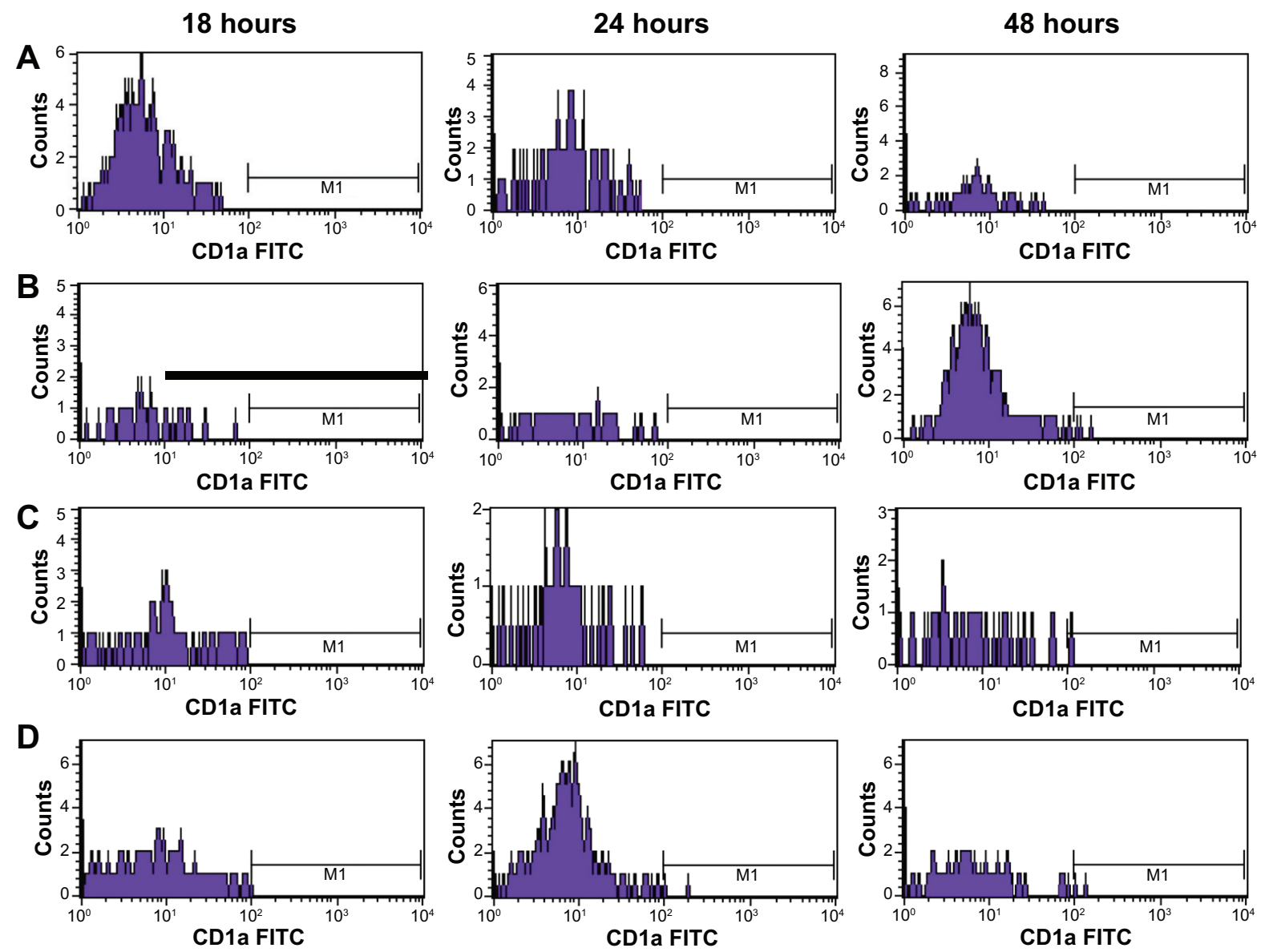

E
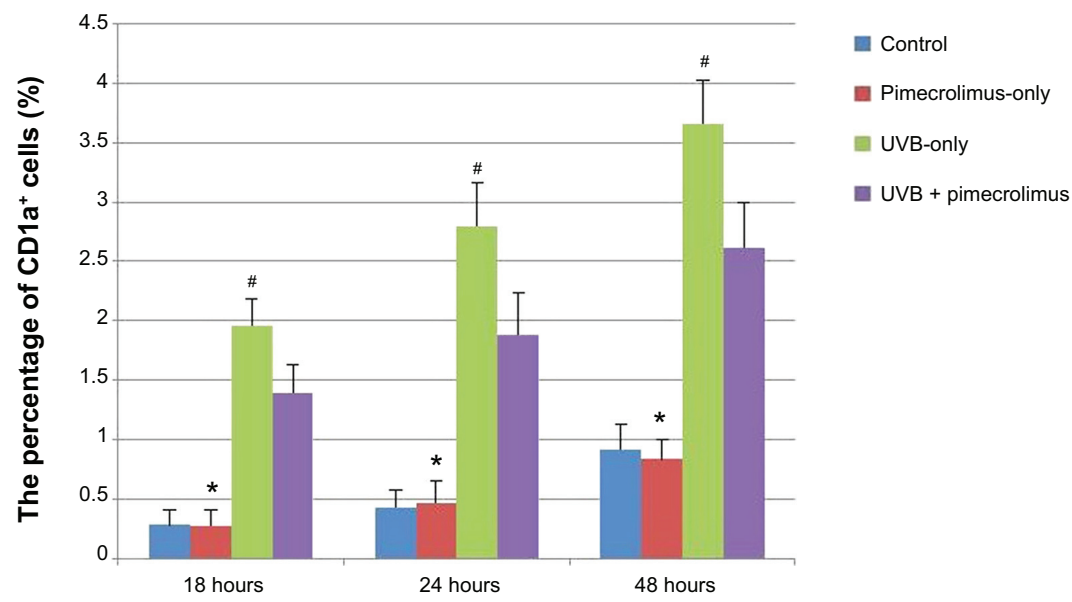

UVB + pimecrolimus

Figure I The percentage of CD la ${ }^{+}$cells was detected by flow cytometry (A-D) and the results of the four groups were compared at the different time points (E). Notes: (A) Control. (B) Pimecrolimus-only. (C) UVB-only. (D) UVB + pimecrolimus. (E) For pimecrolimus-only, the percentage of CD Ia ${ }^{+}$cells had no significant difference compared with the control at 18 hours, 24 hours, and 48 hours; however, *the percentage of CD Ia cells for pimecrolimus-only was significantly less than that for both UVBonly and UVB + pimecrolimus at the same time points $(P<0.0 \mathrm{I})$, and "the CDI a cells of UVB-only were significantly more than that of $U V B+$ pimecrolimus $(P<0.0 \mathrm{I})$. Abbreviation: UV, ultraviolet.

Figure $2 \mathrm{~A}, \mathrm{C}$, and $\mathrm{F}$ shows that at each time point, the mRNA level of IL-1 $\beta$ of the control group had no significant difference compared with the pimecrolimus-only group $(P>0.05)$. The IL-1 $\beta$ mRNA level had a significant increase from 0 hours to 18 hours, 18 hours to 24 hours, and 24 hours to 48 hours $(P<0.01)$, for both the $\mathrm{UVB}+$ pimecrolimus group and UVB-only group. At 18 hours, 24 hours, and 48 hours, the IL- $1 \beta$ mRNA level of the UVB-only group was clearly higher than that of the control group $(P<0.01)$. For the UVB + pimecrolimus group, it was also significantly higher 

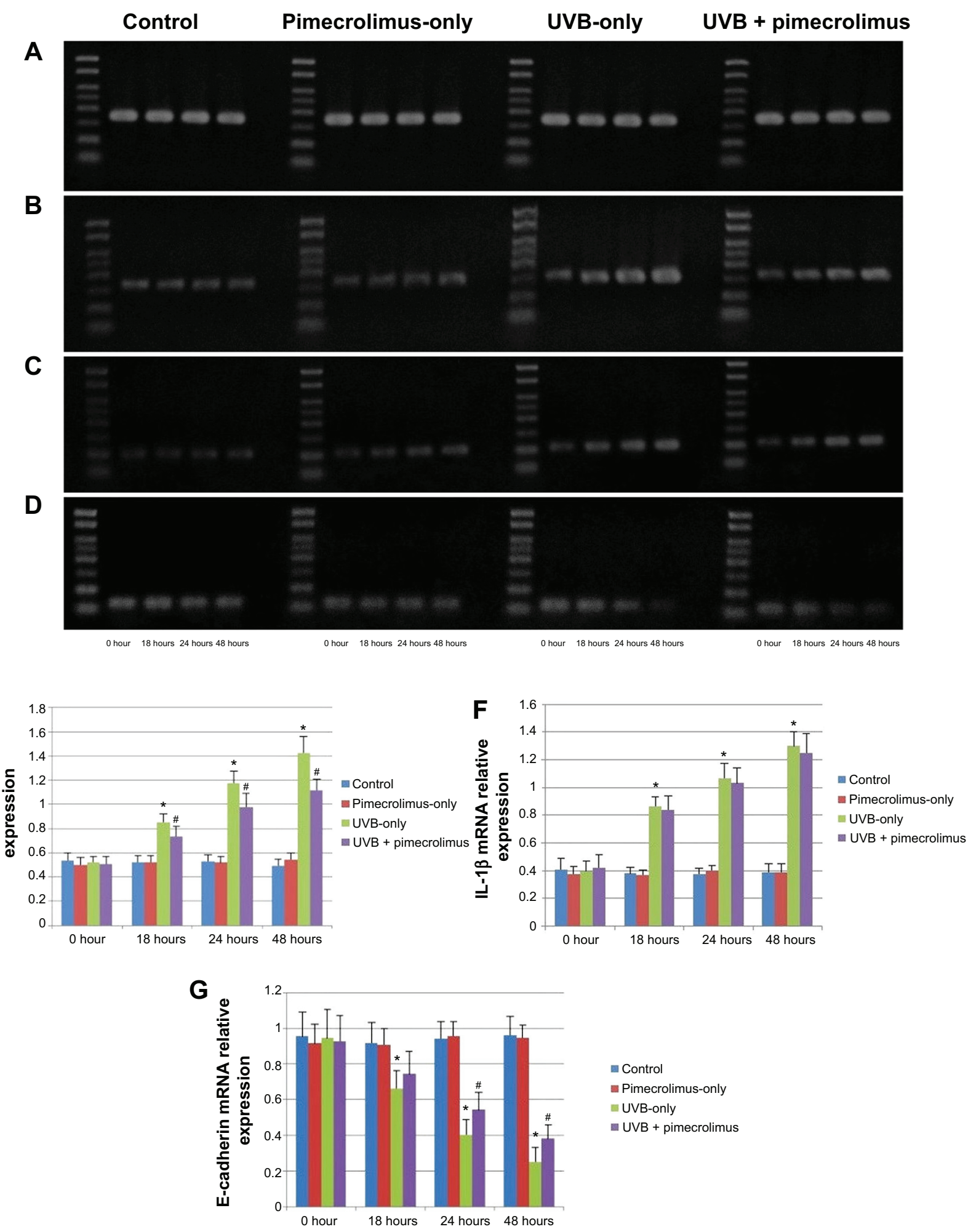

Figure 2 The mRNA expression of TNF- $\alpha$, IL-I $\beta$, and E-cadherin was detected by RT-PCR (A-D) and the results of the four groups were compared at the different time points (E-G).

Notes: (A) GAPDH, 352 bp. (B) TNF- $\alpha, 354$ bp. (C) IL-I $\beta$, 195 bp. (D) E-cadherin, 126 bp. (E) TNF- $\alpha$ mRNA expression. *The TNF- $\alpha$ of UVB-only was clearly higher than that of the control at 18 hours, 24 hours, and 48 hours $(P<0.01)$, and "for UVB + pimecrolimus, TNF- $\alpha$ was significantly lower compared with UVB-only $(P<0.01)$. (F) IL-I $\beta$ mRNA expression. *The IL-I $\beta$ of UVB-only was clearly higher than that of the control at 18 hours, 24 hours, and 48 hours $(P<0.01)$. For UVB + pimecrolimus, there was no significant difference compared with UVB-only. (G) E-cadherin mRNA expression. *The E-cadherin of UVB-only was clearly lower than that of the control at 18 hours, 24 hours, and 48 hours $(P<0.01)$. "For UVB + pimecrolimus, E-cadherin was significantly higher at 24 hours and 48 hours $(P<0.01)$, however, had no significant difference at 18 hours compared with UVB-only.

Abbreviations: mRNA, messenger RNA; TNF, tumor necrosis factor; IL, interleukin; RT-PCR, reverse-transcription polymerase chain reaction; GAPDH, glyceraldehyde3-phosphate dehydrogenase; UV, ultraviolet. 
than for the pimecrolimus-only group and control group at the same time points $(P<0.01)$. However, the IL-1 $\beta$ mRNA level of the UVB + pimecrolimus group had no significant difference compared with the UVB-only group at 18 hours ( $P=0.45), 24$ hours $(P=0.51)$, and 48 hours $(P=0.39)$.

Figure 2A, D, and $\mathrm{G}$ shows that at each time point, the mRNA level of E-cadherin of the control group had no significant difference compared with the pimecrolimus-only group $(P>0.05)$. For both the UVB + pimecrolimus group and UVB-only group, the E-cadherin mRNA level had a significant decrease from 0 hours to 18 hours, 18 hours to 24 hours, and 24 hours to 48 hours $(P<0.01)$ and was clearly lower than that of the control group at 18 hours, 24 hours, and 48 hours $(P<0.01)$. For the UVB + pimecrolimus group, the E-cadherin mRNA level was significantly higher at 24 hours and 48 hours $(P<0.01)$ but was not significantly different at 18 hours $(P=0.119)$ compared with the UVBonly group.

\section{Western blot tests for the protein expression of TNF- $\alpha$ and E-cadherin}

According to RT-PCR results, the mRNA expression of TNF- $\alpha$ and E-cadherin of UVB + pimecrolimus group had obvious difference compared with the UVB-only group. To further validate the difference, we detected the protein expression of TNF- $\alpha$ and E-cadherin by means of Western blot.

Figure $3 \mathrm{~A}, \mathrm{~B}$, and $\mathrm{D}$ show that at each time point, the TNF- $\alpha$ protein level of the control group had no significant difference compared with the pimecrolimus-only group $(P>0.05)$. For both the UVB + pimecrolimus group and UVB-only group, the TNF- $\alpha$ protein level had a significant increase from 0 hours to 18 hours, 18 hours to 24 hours, and 24 hours to 48 hours $(P<0.01)$. At 18 hours, 24 hours, and 48 hours, the TNF- $\alpha$ protein level of the UVB-only group was clearly higher than that of the control group $(P<0.01)$. For the UVB + pimecrolimus group, the TNF- $\alpha$ protein level was also significantly higher than that of both the pimecrolimus-only group and control group at the same time points $(P<0.01)$, however, was clearly lower in comparison with the UVB-only group $(P<0.01)$.

Figure $3 \mathrm{~A}, \mathrm{C}$, and $\mathrm{E}$ showed that at each time point, the E-cadherin protein level of the control group had no significant difference compared with the pimecrolimus-only group $(P>0.05)$. For both the $\mathrm{UVB}+$ pimecrolimus group and UVB-only group, the E-cadherin protein level had a significant decrease from 0 hours to 18 hours, 18 hours to 24 hours, and 24 hours to 48 hours $(P<0.01)$, and was clearly
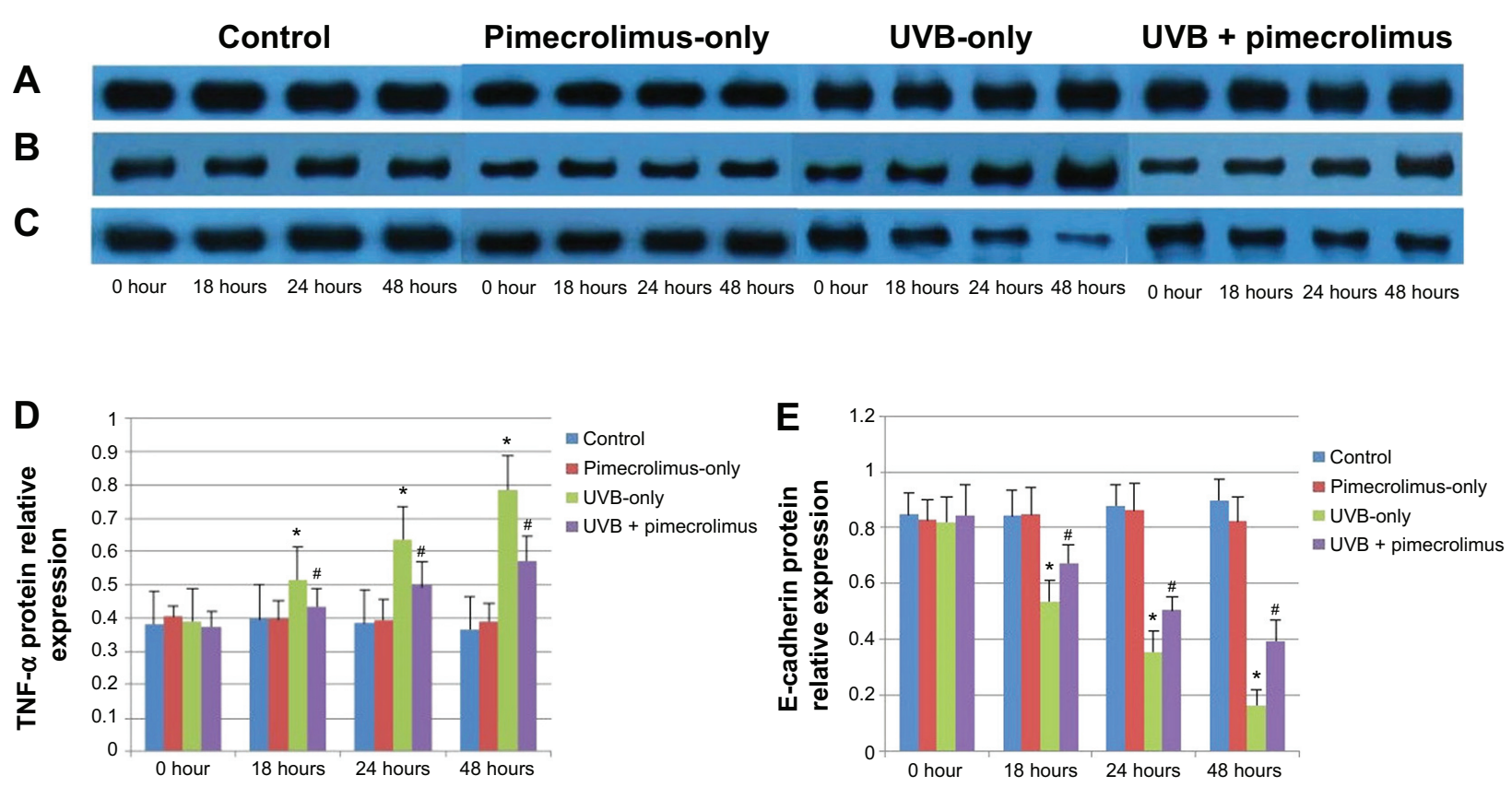

Figure 3 The protein expression of TNF- $\alpha$ and E-cadherin was detected by Western blot $(\mathbf{A}-\mathbf{C})$ and the results of the four groups were compared at the different time points (D and $\mathbf{E})$.

Notes: (A) $\beta$-actin. (B) TNF- $\alpha$. (C) E-cadherin. (D) TNF- $\alpha$ protein expression. *The TNF- $\alpha$ of UVB-only was clearly higher than that of the control at I8 hours, 24 hours, and 48 hours $(P<0.0 \mathrm{I})$. "For UVB + pimecrolimus, TNF- $\alpha$ was significantly lower compared with the UVB-only group $(P<0.0 \mathrm{I})$. (E) E-cadherin protein expression. *The E-cadherin of UVB-only was clearly lower than that of the control at 18 hours, 24 hours, and 48 hours $(P<0.01)$. \#For UVB + pimecrolimus, E-cadherin was significantly higher compared with UVB-only $(P<0.01)$.

Abbreviations: TNF, tumor necrosis factor; UV, ultraviolet. 
lower than that of the control group at 18 hours, 24 hours, and 48 hours $(P<0.01)$. For the UVB + pimecrolimus group, the E-cadherin protein level was significantly higher in comparison with that of the UVB-only group at 18 hours, 24 hours, and 48 hours $(P<0.01)$.

\section{Discussion}

It is well known that UVB irradiation is mainly absorbed by the human epidermis, and only a small part reaches the dermis. UVB mostly acts on the epidermal cells (including LCs) rather than dermal cells during very short irradiation time. Epidermal LCs play a role in immunosurveillance, which is one important pathway against tumorigenesis. They process antigen and migrate to draining lymph nodes, expressing CD1a. ${ }^{9}$ In our experiment, some LCs would migrate into the culture medium during the process of LC migration out of the epidermis. We thought the CD1a cells in the culture medium were mainly migratory epidermal LCs rather than dermal dendritic cells. We detected the percentage of $\mathrm{CD} \mathrm{a}^{+}$cells in the culture medium by flow cytometry, and the results could reflect the difference in epidermal LC migration between different groups and different time points, to a certain extent.

In our study we cultured fresh human foreskin tissues; however, the tissues could not survive for long time. Shortterm, repeated low-dose UVB irradiation could not induce significant epidermal LC reduction, so we used a single high-dose UVB irradiation, which could induce obvious LC change, as was proved by Kölgen et al. ${ }^{4}$ The interval between pimecrolimus application and UVB irradiation in our study was very short. We only applied pimecrolimus after UVB irradiation, to avoid the effect of possible light-absorbing activity of pimecrolimus.

Pimecrolimus is a lipophilic drug with good skin absorption. After the external use of pimecrolimus, its blood concentration is very low. Accordingly, its metabolism is unmeasurable after external use. In our experiment, prolonged exposure to air could affect the survival of the tissues; therefore, 10 minutes after application, culture medium was added to immerse the whole tissue. To increase the absorption of the drug, we kept dabbing with pressure for 30 seconds, when a thin layer of pimecrolimus was delivered to the epidermis, using sterile cotton swab. A portion of pimecrolimus might have been washed off the epidermis once the skin samples were placed in media; however, a portion of medicine had been absorbed by skin, so we believe the experimental results were not affected because each group was under the same experimental condition.
Flow cytometry showed that from 0 hours to 48 hours, the percentage of CD1 $\mathrm{a}^{+}$cells had a significantly increasing trend for the control group and pimecrolimus-only group, and there were no significant difference between the two groups; this indicated that epidermis LCs were not stationary and still had dynamic migration behavior while the tissues were cultured at $37^{\circ} \mathrm{C}$, and simple pimecrolimus did not affect epidermal LC migration. Flow cytometry also showed that high-dose UVB irradiation could promote LC migration out of the epidermis, while topical pimecrolimus could inhibit epidermal LC migration induced by high-dose UVB irradiation, to a certain degree.

We detected the mRNA expression of cytokines and other molecules (TNF- $\alpha$, IL-1 $\beta$, and E-cadherin) related to LC migration in the cultured tissues by means of RTPCR. RT-PCR showed that simple pimecrolimus did not affect the mRNA expression of TNF- $\alpha$, IL-1 $\beta$, and E-cadherin. Single high-dose UVB irradiation was able to increase the mRNA expression of TNF- $\alpha$ and IL- $1 \beta$ and decrease the mRNA expression of E-cadherin. Topical pimecrolimus could fight against the effects of high-dose UVB irradiation on the mRNA expression of TNF- $\alpha$ and E-cadherin.

According to the results of RT-PCR, we validated TNF- $\alpha$ and E-cadherin, at the protein level, using Western blot. Western blot showed that simple pimecrolimus did not affect the protein expression of TNF- $\alpha$ and E-cadherin. Single high-dose UVB irradiation was able to increase the protein expression of TNF- $\alpha$ and decrease the protein expression of E-cadherin. Topical pimecrolimus could fight against the effects of high-dose UVB irradiation on the protein expression of TNF- $\alpha$ and E-cadherin.

Upregulation of TNF- $\alpha$ and IL- $1 \beta$ and downregulation of E-cadherin could promote LC migration from epidermis to dermis. TNF- $\alpha$ can promote LC migration via downregulation of E-cadherin. ${ }^{10} \mathrm{We}$ confirmed that a single high-dose UVB irradiation could promote the epidermal LC migration, by flow cytometry. RT-PCR and Western blot also proved that the mechanism of LC migration induced by UVB irradiation was related to the increase of IL-1 $\beta$ and TNF- $\alpha$ and the decrease of E-cadherin. In contrast, topical pimecrolimus inhibited the increase of TNF- $\alpha$ and the decrease of E-cadherin induced by UVB irradiation, which was the possible mechanism for the inhibitory effect of pimecrolimus on epidermal LC migration induced by highdose UVB irradiation.

Tacrolimus inhibits TNF- $\alpha$ secretion in human keratinocytes, via regulation of nuclear factor-kappaB. ${ }^{11}$ Does 
pimecrolimus have the same effect as tacrolimus? It is unclear at present and needs further study.

It is well known that topical calcineurin inhibitors, including pimecrolimus and tacrolimus, block T cell proliferation. Meingassner et $\mathrm{al}^{12}$ reported that pimecrolimus cream had no effect on LCs in murine epidermis because no changes in number or morphology of LCs were observed in epidermal sheets of mice treated for 5 days with pimecrolimus; in contrast, an almost complete depletion of LCs was observed in skin samples treated with hydrocortisone, betamethasone, or clobetasol. Our study also observed that simple pimecrolimus had no effect on the experimental results; however, it inhibited epidermal LC migration induced by single high-dose UVB irradiation, which indicated that topical pimecrolimus might have immunoregulation effect under some special conditions, such as UV irradiation. This outcome has not been reported before, thus brings a new understanding about the mechanism of pimecrolimus's action on skin cells. Epidermal LC-mediated immunosurveillance is one important pathway against tumorigenesis. LCs perform antigen presentation, where immature epidermal LCs discern and ingest antigen, then maturing gradually and migrating to the draining lymph nodes. If pimecrolimus inhibits epidermal LC migration induced by UVB irradiation, then, could pimecrolimus increase photocarcinogenesis? This also needs further study.

Topical pimecrolimus $1 \%$ was able to inhibit epidermal LC migration induced by single high-dose UVB irradiation, where the possible mechanism might be the inhibition of the increase of TNF- $\alpha$ expression and the decrease of E-cadherin expression induced by high-dose UVB irradiation. It is true that upregulation of TNF- $\alpha$ and IL-1 $\beta$ and downregulation of E-cadherin facilitate migration of LCs out of the epidermis by promoting maturation. However the shift in chemokine receptors at cell surface is of crucial importance. Normally, skinhoming chemokine receptors, such as CCR1, CCR2, CCR5, and CCR6, are downregulated, and CCR4, CXCR4, and CCR7 are upregulated. ${ }^{13-19}$ In addition, IL-18, $\alpha-6$ integrins, MMP-9, and CCR7 ligand CCL19 also facilitate epidermal LC migration. ${ }^{5,20-22}$ Further work is needed to investigate other cytokines, adhesion molecules, chemokines, and chemokine receptors related to LC migration.

\section{Acknowledgments}

This work was supported by the National Natural Science Foundation of China (grant numbers 81171518 and 81301387) and the Priority Academic Program Development of Jiangsu Higher Education Institutions (grant number JX10231801).

\section{Disclosure}

The authors report no conflicts of interest in this work.

\section{References}

1. Goldstein AT, Thaçi D, Luger T. Topical calcineurin inhibitors for the treatment of vulvar dermatoses. Eur J Obstet Gynecol Reprod Biol. 2009;146(1):22-29.

2. Martires KJ, Domingo DS, Hsia A, Fu P, Cooper KD, Baron ED. Effects of pimecrolimus versus triamcinolone on Langerhans cells after UV exposure. Exp Dermatol. 2011;20(3):280-282.

3. Yin Z, Xu J, Zhang Z, Luo D. Effects of topical pimecrolimus $1 \%$ on high-dose ultraviolet B-irradiated epidermal Langerhans cells. Int Immunopharmacol. 2012;14(4):635-640.

4. Kölgen W, Both $\mathrm{H}$, van Weelden $\mathrm{H}$, et al. Epidermal Langerhans cell depletion after artificial ultraviolet $\mathrm{B}$ irradiation of human skin in vivo: apoptosis versus migration. J Invest Dermatol. 2002;118(5):812-817.

5. Antonopoulos C, Cumberbatch M, Mee JB, et al. IL-18 is a key proximal mediator of contact hypersensitivity and allergen-induced Langerhans cell migration in murine epidermis. J Leukoc Biol. 2008;83(2):361-367.

6. Cumberbatch M, Dearman RJ, Kimber I. Adhesion molecule expression by epidermal Langerhans cells and lymph node dendritic cells: a comparison. Arch Dermatol Res. 1996;288(12):739-744.

7. Ostberg JR, Kabingu E, Repasky EA. Thermal regulation of dendritic cell activation and migration from skin explants. Int $J$ Hyperthermia. 2003;19(5):520-533.

8. Bradford MM. A rapid and sensitive method for the quantitation of microgram quantities of protein utilizing the principle of protein-dye binding. Anal Biochem. 1976;72:248-254.

9. Rowden G. Expression of Ia antigens on Langerhans cells in mice, guinea pigs, and man. J Invest Dermatol. 1980;75(1):22-31.

10. Jakob T, Udey MC. Regulation of E-cadherin-mediated adhesion in Langerhans cell-like dendritic cells by inflammatory mediators that mobilize Langerhans cells in vivo. J Immunol. 1998;160(8):4067-4073.

11. Lan CC, Yu HS, Wu CS, Kuo HY, Chai CY, Chen GS. FK506 inhibits tumour necrosis factor-alpha secretion in human keratinocytes via regulation of nuclear factor-kappaB. Br J Dermatol. 2005;153(4):725-732.

12. Meingassner JG, Kowalsky E, Schwendinger H, Elbe-Bürger A, Stütz A. Pimecrolimus does not affect Langerhans cells in murine epidermis. Br J Dermatol. 2003;149(4):853-857.

13. Yamagami S, Hamrah P, Miyamoto K, et al. CCR5 chemokine receptor mediates recruitment of MHC class II-positive Langerhans cells in the mouse corneal epithelium. Invest Ophthalmol Vis Sci. 2005;46(4): 1201-1207.

14. Sato N, Ahuja SK, Quinones M, et al. CC chemokine receptor (CCR)2 is required for Langerhans cell migration and localization of $\mathrm{T}$ helper cell type 1 (Th1)-inducing dendritic cells. Absence of CCR2 shifts the Leishmania major-resistant phenotype to a susceptible state dominated by Th2 cytokines, b cell outgrowth, and sustained neutrophilic inflammation. J Exp Med. 2000;192(2):205-218.

15. Matsuzawa T, Kawamura T, Ogawa Y, etal. Oral administration of the CCR5 inhibitor, maraviroc, blocks HIV ex vivo infection of Langerhans cells within the epithelium. J Invest Dermatol. 2013;133(12):2803-2805.

16. Fleming MD, Pinkus JL, Fournier MV, et al. Coincident expression of the chemokine receptors CCR6 and CCR7 by pathologic Langerhans cells in Langerhans cell histiocytosis. Blood. 2003;101(7):2473-2475.

17. Stutte S, Quast T, Gerbitzki N, et al. Requirement of CCL17 for CCR7and CXCR4-dependent migration of cutaneous dendritic cells. Proc Natl Acad Sci U S A. 2010;107(19):8736-8741

18. Villablanca EJ, Mora JR. A two-step model for Langerhans cell migration to skin-draining LN. Eur J Immunol. 2008;38(11):2975-2980. 
19. Ohl L, Mohaupt M, Czeloth N, et al. CCR7 governs skin dendritic cell migration under inflammatory and steady-state conditions. Immunity 2004;21(2):279-288

20. Price AA, Cumberbatch M, Kimber I, Ager A. Alpha 6 integrins are required for Langerhans cell migration from the epidermis. $J$ Exp Med. 1997;186(10):1725-1735.
21. Koch S, Kohl K, Klein E, von Bubnoff D, Bieber T. Skin homing of Langerhans cell precursors: adhesion, chemotaxis, and migration. J Allergy Clin Immunol. 2006;117(1):163-168.

22. Randolph GJ. Dendritic cell migration to lymph nodes: cytokines, chemokines, and lipid mediators. Semin Immunol. 2001;13(5):267-274.

\section{Publish your work in this journal}

Drug Design, Development and Therapy is an international, peerreviewed open-access journal that spans the spectrum of drug design and development through to clinical applications. Clinical outcomes, patient safety, and programs for the development and effective, safe, and sustained use of medicines are a feature of the journal, which has also been accepted for indexing on PubMed Central. The manuscript management system is completely online and includes a very quick and fair peer-review system, which is all easy to use. Visit http://www.dovepress.com/testimonials.php to read real quotes from published authors.

Submit your manuscript here: http://www.dovepress.com/drug-design-development-and-therapy-journal 